Pacific Journal of Mathematic 


\title{
A NECESSARY AND SUFFICIENT CONDITION FOR UNIQUENESS OF SOLUTIONS TO TWO POINT BOUNDARY VALUE PROBLEMS
}

\author{
Dennis Barr and Peter Miletta
}

In this paper it is shown that the uniqueness of solutions to two point boundary value problems in which one end point is held fixed is equivalent to the existence of a family of Liapunov functions.

T. Yoshizawa [6] and H. Okamura [5] demonstrated that the uniqueness of solutions to initial value problems was equivalent to existence of a Liapunov function. J. Kato and A. Strauss [4] and S. Bernfeld [1] provided necessary and sufficient conditions for the existence of solutions to initial value problems on $\left[t_{0}, \infty\right)$ with the use of Liapunov functions. With regard to boundary value problems J. H. George and W. G. Sutton [2] obtained a sufficient condition in terms of a Liapunov function for the existence and uniqueness of solutions to two point boundary value problems. In this paper we shall employ a variation of the Okamura function to obtain a generalization of the latter result for a certain class of two point boundary value problems.

1. Preliminaries. In this section we state the definition of a Liapunov function and establish a theorem which will be used in the next section. We shall consider the second order differential equation:

$$
x^{\prime \prime}=f\left(t, x, x^{\prime}\right),
$$

where $f$ is a real-valued function defined and continuous on $[a, b] \times$ $R^{2}$. It will be assumed that initial value problems associated with (1) exist, are unique, and that solutions are defined throughout $[a, b]$. In particular we shall be concerned with the uniqueness of solutions to (1) satisfying

$$
x\left(t_{1}\right)=y_{1} \quad x\left(t_{2}\right)=y_{2}
$$

where $a \leqq t_{1}<t_{2} \leqq b$ and $y_{1}, y_{2} \in R$. If $x_{0}(t)$ is any solution of (1) satisfying (2) for some points $t_{1}$, and $t_{2}$, then by setting $x(t)=$ $y(t)+x_{0}(t)$ we obtain

$$
y^{\prime}(t)=F\left(t, y(t), y^{\prime}(t)\right),
$$

where $F\left(t, y(t), y^{\prime}(t)\right)=f\left(t, y(t)+x_{0}(t), y^{\prime}(t)+x_{0}^{\prime}(t)\right)-f\left(t, x_{0}(t), x_{0}^{\prime}(t)\right)$. 
Thus equation (1) has a unique solution satisfying (2) if and only if $y(t)=0$ is the only solution of (3) such that $y\left(t_{1}\right)=y\left(t_{2}\right)=0$. Thus we shall restrict our attention to the differential equation

$$
x^{\prime \prime}=F\left(t, x, x^{\prime}\right),
$$

where $F(t, 0,0)=0$ and the boundary conditions

$$
x\left(t_{1}\right)=x\left(t_{2}\right)=0 .
$$

The principal tool employed in this paper will be Liapunov functions.

Definition. A Liapunov function for (4) is a real valued function $V$ defined on $D=[a, b] \times S$ where $S$ is a closed subset of $R^{2}$ and $(0,0) \in S$, such that

$$
\begin{aligned}
& V\left(t, 0, x_{2}\right)=0 \\
& V\left(t, x_{1}, x_{2}\right)>0 \text { if } x_{1} \neq 0 \\
& V\left(t, x_{1}, x_{2}\right) \text { is nondecreasing along solution curves of (4) }
\end{aligned}
$$

By condition (8) we shall mean that if $x(t)$ is a solution of (4), then $V\left(t_{1}, x\left(t_{1}\right), x^{\prime}\left(t_{1}\right)\right) \leqq V\left(t_{2}, x\left(t_{2}\right), x^{\prime}\left(t_{2}\right)\right)$ for all points $t_{1}$ and $t_{2}$, $t_{1}<t_{2}$, such that $\left(t_{i}, x\left(t_{i}\right), x^{\prime}\left(t_{i}\right)\right) \in D$.

If $V$ is a real valued function satisfying (6) and (7), then the following theorem provides a sufficient condition for $V$ to be a Liapunov function.

THEOREM 1. Suppose $V$ is continuous and satisfies a Lipschitz condition locally with respect to $x_{1}$ and $x_{2}$ in $D$, and

$$
\begin{aligned}
V(t, & \left.x_{1}, x_{2}\right) \\
& =\frac{\lim }{h \rightarrow 0^{+}}+\frac{1}{h}\left[V\left(t+h, x_{1}+h x_{2}, x_{2}+h F\left(t, x_{1}, x_{2}\right)\right)-V\left(t, x_{1}, x_{2}\right)\right] \geqq 0
\end{aligned}
$$

for $t, x_{1}, x_{2}$ in the interior of $D$. Then $V\left(t, x_{1}, x_{2}\right)$ is nondecreasing along solution curves of (4).

Proof. Yoshizawa [6].

The following theorem gives a sufficient condition for the uniqueness of solutions of (4) satisfying (5).

Theorem 2. Suppose $V\left(t, x_{1}, x_{2}\right)$ is a Liapunov function for (4) defined on $[a, b] \times R^{2}$. Then for any $t_{1}$ and $t_{2}, a \leqq t_{1}<t_{2} \leqq b$, there exists at most one solution to (4) satisfying (5). 
Proof. Employing a stronger definition of a Liapunov function George and Sutton [2] have given a proof of this theorem. We include a proof for referral at a later time. Suppose $y(t)$ is a nonzero solution of (4) satisfying (5). Then there exists a $t_{0} \in\left(t_{1}, t_{2}\right)$ such that $y\left(t_{0}\right) \neq 0$. Thus $V\left(t_{0}, y\left(t_{0}\right), y^{\prime}\left(t_{0}\right)\right)>0$. However $y\left(t_{2}\right)=0$ implies that $V\left(t_{2}, y\left(t_{2}\right), y^{\prime}\left(t_{2}\right)\right)=0$. This is a contradiction to the assumption that $V\left(t, x_{1}, x_{2}\right)$ is nondecreasing along the solution curves of (4).

Two known conditions insuring the uniqueness of solutions of (4) satisfying (5) are consequences of Theorem 2. Hartman [3, page 433] proved that if $\left(x^{\prime}(t)\right)^{2}+x(t) F\left(t, x(t), x^{\prime}(t)\right)>0$ wherever $x(t) \neq 0$ and $x^{\prime}(t) x^{\prime \prime}(t)=0$, for all solutions $x(t)$ of (4) then $x(t)=0$ is the only solution of (4) satisfying (5). It was noted by George and Sutton that $V\left(t, x_{1}, x_{2}\right)=\left(x_{1}\right)^{2}$ satisfied their definition of a Liapunov function and therefore by Theorem 2 the result of Hartman follows. The same choice for $V\left(t, x_{1}, x_{2}\right)$ will satisfy our definition. It is also well known that if $F\left(t, x_{1}, x_{2}\right)$ is continuous and strictly increasing in $x_{1}$ for fixed $\left(t, x_{2}\right)$ then $x(t)=0$ is the only solution of (4) satisfying (5). This result also follows from Theorem 2 by choosing

$$
V\left(t, x_{1}, x_{2}\right)=\int_{a}^{t}\left|F\left(s, x_{1}, x_{2}\right)-F\left(s, 0, x_{2}\right)\right| d s .
$$

2. Necessary and sufficient condition. In this section we will further restrict our attention to the boundary value problem

$$
\begin{aligned}
x^{\prime \prime} & =F\left(t, x, x^{\prime}\right) \\
x(\alpha) & =0 \quad x(\gamma)=0,
\end{aligned}
$$

where $F(t, 0,0)=0$ and $a<\gamma \leqq b$. Thus we shall fix $t_{1}=a$. We now proceed to derive a necessary and sufficient condition for the uniqueness of solutions of (9) satisfying (10).

For each $M>0$ let $D_{M}$ denote the subset of $[a, b] \times R^{2}$ defined by $D_{M}=\{(t, \alpha, \beta): 2|\alpha /(t-a)| \leqq M, 2|\alpha /(t-b)| \leqq M, 2|\beta| \leqq M\} \cup$ $\{(a, 0, \beta): 2|\beta| \leqq M\} \cup\{(b, 0, \beta): 2|\beta| \leqq M\}$. For each $\left(t_{0}, \alpha, \beta\right) \in D_{M}$, $a<t_{0}<b$, let $X_{\left(t_{0}, \alpha, \beta\right)}^{M}$ denote the set of all continuously differentiable functions $x(t)$ defined on $[a, b]$ whose second derivative exists and is continuous for all except at most one point of $[a, b]$ and which satisfy $\left|x^{\prime}(t)\right| \leqq M$ for all $t \in[a, b], x(a)=x(b)=0, x\left(t_{0}\right)=\alpha$, and $x^{\prime}\left(t_{0}\right)=\beta$. The restrictions on $\left(t_{0}, \alpha, \beta\right)$ in the definition of $D_{M}$ insure that $X_{\left(t_{0}, \alpha, \beta\right)}^{M}$ is not empty.

Lemma 1. Suppose $a<t_{0}<b$. There exists a solution to (9) 
satisfying $x(a)=x(b)=0, x\left(t_{0}\right)=\alpha$, and $x^{\prime}\left(t_{0}\right)=\beta$ if and only if

$$
\underset{x(t) \in X_{\left(t_{0}, \alpha, \beta\right)}^{M}}{\operatorname{infmum}} \int_{a}^{b}\left|x^{\prime \prime}(t)-F\left(t, x(t), x^{\prime}(t)\right)\right| d t=0
$$

for some $M$.

Proof. If there exists a solution to (9) satisfying the above conditions then for some $M>0, x(t) \in X_{\left(t_{0}, \alpha, \beta\right)}^{M}$. For this $M$, or any larger $M$, the above infimum will be zero. Conversely suppose the above infimum is zero for some $M>0$. Let $\left\{x_{k}(t)\right\}$ be a sequence of functions in $X_{\left(t_{0}, \alpha, \beta\right)}^{M}$ such that

$$
\lim _{k \rightarrow \infty} \int_{a}^{b}\left|x_{k}^{\prime \prime}(t)-F\left(t, x_{k}(t), x_{k}^{\prime}(t)\right)\right| d t=0 .
$$

Letting $y_{k}(t)=\int_{a}^{t}\left(x_{k}^{\prime \prime}(s)-F\left(s, x_{k}(s), x_{k}^{\prime}(s)\right)\right) d s$ we see by (12) that $y_{k}(t)$ converges to zero uniformly on $[a, b]$. Let $z_{k}(t)=x_{k}(t)-\int_{a}^{t} y_{k}(s) d s$. Then $z_{k}^{\prime}(t)=x_{k}^{\prime}(t)-y_{k}(t)=x_{k}^{\prime}(a)+\int_{a}^{t} F\left(s, x_{k}(s), x_{k}^{\prime}(s)\right) d s$ and for $a \leqq$ $t_{1}<t_{2} \leqq b$

$$
\left|z_{k}^{\prime}\left(t_{1}\right)-z_{k}^{\prime}\left(t_{2}\right)\right| \leqq \int_{t_{1}}^{t_{2}}\left|F\left(s, x_{k}(s), x_{k}^{\prime}(s)\right)\right| d s \leqq K_{M}\left|t_{2}-t_{1}\right|,
$$

where $K_{M}=\max _{\left(t, x_{1}, x_{2}\right) \in D_{M}}\left|F\left(t, x_{1}, x_{2}\right)\right|$. Also

$$
\left|z_{k}^{\prime}(t)\right| \leqq M+K_{M}(b-a) \text {. }
$$

Therefore, there exists a uniformly convergent subsequence of $\left\{z_{k}^{\prime}(t)\right\}$ which we shall again denote by $\left\{z_{k}^{\prime}(t)\right\}$. In a similar manner the sequence of functions $\left\{z_{k}(t)\right\}$ can easily be shown to be equicontinuous and uniformly bounded. Thus we again obtain a subsequence which we denote by $\left\{z_{k}(t)\right\}$, such that $\left\{z_{k}(t)\right\}$ and $\left\{z_{k}^{\prime}(t)\right\}$ converge uniformly on $[a, b]$. Denote the limit function by $z(t)$. Since $z_{k}(a)=0$ for all $k$, we have that $z(a)=0$. Also $y_{k}(t)$ converges to 0 uniformly on $[a, b]$ implies that $x_{k}(t)$ converges uniformly to $z(t)$ and $x_{k}^{\prime}(t)$ converges uniformly to $z^{\prime}(t)$ on $[a, b]$.

Thus $z(b)=0, z\left(t_{0}\right)=\alpha$, $z^{\prime}\left(t_{0}\right)=\beta$, and

$$
z^{\prime \prime}(t)=F\left(t, z(t), z^{\prime}(t)\right)
$$

Thus $z(t)$ is a solution with the desired properties.

For each $M>0$ we define a real valued function $V_{M}$ with domain $D_{M}$ by 


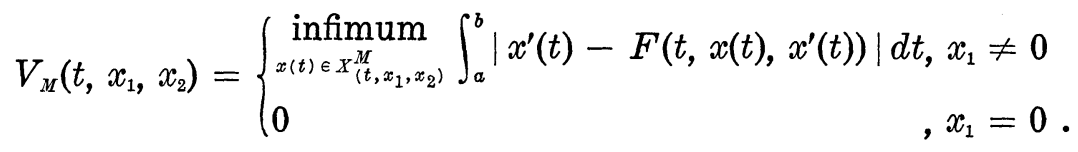

THEOREM 3. Suppose that there exists at most one solution to (9) satisfying (10) for every $\gamma, a<\gamma \leqq b$. Then for each $M>0, V_{M}$ satisfies the following conditions:

$$
\begin{gathered}
V_{M}\left(t, 0, x_{2}\right)=0 \\
V_{M}\left(t, x_{1}, x_{2}\right)>0 \quad \text { if } x_{1} \neq 0
\end{gathered}
$$

(16) $V_{M}\left(t, x_{1}, x_{2}\right)$ is nondecreasing along solution curves $x(t)$ of (9) which satisfy $x(a)=0$ and $\left(t, x(t), x^{\prime}(t)\right) \in D_{M}$ for all $t \in[a, b]$.

Proof. $V_{M}$ clearly satisfies (14). Suppose $x_{1} \neq 0$ and $V_{M}\left(t, x_{1}, x_{2}\right)=$ 0 . Then by Lemma 1 there exists a solution $x(t)$ of (9) such that $x(a)=x(b)=0$ and $x(t)=x_{1}$. This contradicts the uniqueness assumption. Thus $V_{M}$ satisfies condition (15). Let $x(t)$ be a solution of (9) such that $\left(t, x(t), x^{\prime}(t)\right) \in D_{M}$ for all $t \in[a, b]$ and $x(a)=0$. Let $a \leqq t_{1}<t_{2} \leqq b$. If $t_{1}=a$ or $t_{2}=b$ then it follows trivially from the uniqueness of solutions of (9) satisfying (10), the uniqueness of initial value problems associated with (9), and properties (14) and (15) that $V_{M}\left(t_{1}, x\left(t_{1}\right), x^{\prime}\left(t_{1}\right)\right) \leqq V_{M}\left(t_{2}, x\left(t_{2}\right), x^{\prime}\left(t_{2}\right)\right)$. Thus assume that $a<t_{1}<t_{2}<b$. Again from uniqueness of solutions of (9) satisfying (10) it follows that $x\left(t_{1}\right) \neq 0$ and $x\left(t_{2}\right) \neq 0$. For each $y(t) \in X_{\left(t_{1}, x\left(t_{1}\right), x^{\prime}\left(t_{1}\right)\right)}^{M}$ the function

$$
z(t)= \begin{cases}x(t) & a \leqq t \leqq t_{1} \\ y(t) & t_{1}<t \leqq b\end{cases}
$$

is again an element of $X_{\left(t_{1}, x\left(t_{1}\right), x^{\prime}\left(t_{1}\right)\right)}^{M}$. Therefore

$$
V_{M}\left(t_{1}, x\left(t_{1}\right), x^{\prime}\left(t_{1}\right)\right)=\operatorname{infimum}_{x(t) \in X_{\left(t_{1}, x\left(t_{1}\right), x^{\prime}\left(t_{1}\right)\right)}^{M}} \int_{t_{1}}^{b}\left|x^{\prime \prime}(t)-F\left(t, x(t), x^{\prime}(t)\right)\right| d t
$$

and in a similar manner

$$
V_{M}\left(t_{2}, x\left(t_{2}\right), x^{\prime}\left(t_{2}\right)\right)=\operatorname{infimum}_{x(t) \in X_{\left(t_{2}, x\left(t_{2}\right), x^{\prime}\left(t_{2}\right)\right)}} \int_{t_{2}}^{b}\left|x^{\prime \prime}(t)-F\left(t, x(t), x^{\prime}(t)\right)\right| d t .
$$

Let $\left\{x_{k}(t)\right\}$ be a sequence in $X_{\left(t_{2}, x\left(t_{2}\right), x^{\prime}\left(t_{2}\right)\right)}^{M}$ such that

$$
V_{M}\left(t_{2}, x\left(t_{2}\right), x^{\prime}\left(t_{2}\right)\right)=\lim _{k \rightarrow \infty} \int_{t_{2}}^{b}\left|x_{k}^{\prime \prime}(t)-F\left(t, x_{k}(t), x_{k}^{\prime}(t)\right)\right| d t .
$$

Then if 


$$
y_{k}(t)= \begin{cases}x(t) & a \leqq t \leqq t_{2} \\ x_{k}(t) & t_{2}<t \leqq b\end{cases}
$$

we have

$$
\begin{aligned}
V_{M}\left(t_{1}, x\left(t_{1}\right), x^{\prime}\left(t_{1}\right)\right) & \leqq \lim _{k \rightarrow \infty} \int_{t_{1}}^{b}\left|y_{k}^{\prime \prime}(t)-F\left(t, y_{k}(t), y_{k}^{\prime}(t)\right)\right| d t \\
& =\lim _{k \rightarrow \infty} \int_{t_{2}}^{b}\left|x_{k}^{\prime \prime}(t)-F\left(t, x_{k}(t), x_{k}^{\prime}(t)\right)\right| d t \\
& =V\left(t_{2}, x\left(t_{2}\right), x^{\prime}\left(t_{2}\right)\right) .
\end{aligned}
$$

Thus $V_{M}$ satisfies (16).

On the other hand if there exists a family of subsets $[a, b] \times$ $S_{M}=D_{M}, S_{M}$ closed, of $[a, b] \times R^{2}$ such that every solution $x(t)$ of (9) satisfies $\left(t, x(t), x^{\prime}(t)\right) \in D_{M}$ for some $M$ and a family of real valued functions $V_{M}$ defined on $D_{M}$ and satisfying (14), (15), and (16), then the only solution of (9) satisfying (10) for any $\gamma \in(a, b]$ is identically zero on $[a, b]$. The proof of this is exactly the same as the proof of Theorem 2. Note that condition (16) is weaker than condition (8).

THEOREM 4. There exists at most one solution of (9) satisfying (10) for all $\gamma \in(a, b]$ if and only if there exists a family of subsets $D_{M}=[a, b] \times S_{M}$ of $[a, b] \times R^{2}$ such that every solution $x(t)$ of (9) satisfies $\left(t, x(t), x^{\prime}(t)\right) \in D_{M}$ for some $M$ and a family of real valued functions $V_{M}$ defined on $D_{M}$ satisfying condition (14), (15), and (16).

Note that a similar theorem to Theorem 4 can be proved if the right end point is fixed.

\section{REFERENCES}

1. S. Bernfeld, Liapunov functions and global existence, Proc. Amer. Math. Soc., 25 (1970), 571-577.

2. J. H. George and W. G. Sutton, Application of Liapunov theory to boundary value problems, Proc. Amer. Math. Soc., 25 (1970), 666-671.

3. P. Hartman, Ordinary Differential Equations, Wiley, New York, 1964.

4. J. Kato and A. Strauss, On the global existence of solutions and Liapunov functions, Ann. Mat. Pure Appl., (4) 77 (1967), 303-316.

5. H. Okamura, Condition necessaire et suffisante remplie par les equations differentielles ordinaires sans points de Peano, Mem. Coll. Sci. Kyoto Imperial Univ., Series A 24 (1942), 21-28.

6. T. Yoshizawa, Stability theory by Liapunov's second method, Publ. Math. Soc. Japan, no. 9, Math. Soc. Japan, Tokyo, 1966.

Received June 24, 1974.

UNIVERSITY OF PUERTO RICO 


\section{PACIFIC JOURNAL OF MATHEMATICS}

\section{EDITORS}

RICHARD ARENS (Managing Editor)

University of California

Los Angeles, California 90024

\section{J. DugundJI}

Department of Mathematics University of Southern California Los Angeles, California 90007

D. Gilbarg and J. Milgram

Stanford University

Stanford, California 94305
University of Washington Seattle, Washington 98105

\section{ASSOCIATE EDITORS}
E. F. BECKENBACH
B. H. NeumanN
F. WolF
K. YoShIDA

\section{SUPPORTING INSTITUTIONS}

\author{
UNIVERSITY OF SOUTHERN CALIFORNIA \\ STANFORD UNIVERSITY \\ UNIVERSITY OF TOKYO \\ UNIVERSITY OF UTAH \\ WASHINGTON STATE UNIVERSITY \\ UNIVERSITY OF WASHINGTON \\ $\stackrel{*}{*} \stackrel{*}{*} \stackrel{*}{ }{ }^{*}$ AMERICAN MATHEMATICAL SOCIETY
}

The Supporting Institutions listed above contribute to the cost of publication of this Journal, but they are not owners or publishers and have no responsibility for its content or policies.

Mathematical papers intended for publication in the Pacific Journal of Mathematics should be in typed form or offset-reproduced, (not dittoed), double spaced with large margins. Underline Greek letters in red, German in green, and script in blue. The first paragraph or two must be capable of being used separately as a synopsis of the entire paper. Items of the bibliography should not be cited there unless absolutely necessary, in which case they must be identified by author and Journal, rather than by item number. Manuscripts, in triplicate, may be sent to any one of the editors. Please classify according to the scheme of Math. Reviews, Index to Vol. 39. All other communications should be addressed to the managing editor, or Elaine Barth, University of California, Los Angeles, California, 90024.

The Pacific Journal of Mathematics expects the author's institution to pay page charges, and reserves the right to delay publication for nonpayment of charges in case of financial emergency.

100 reprints are provided free for each article, only if page charges have been substantially paid. Additional copies may be obtained at cost in multiples of 50 .

The Pacific Journal of Mathematics is issued monthly as of January 1966. Regular subscription rate: $\$ 72.00$ a year (6 Vols., 12 issues). Special rate: $\$ 36.00$ a year to individual members of supporting institutions.

Subscriptions, orders for back numbers, and changes of address should be sent to Pacific Journal of Mathematics, 103 Highland Boulevard, Berkeley, California, 94708.

\section{PUBLISHED BY PACIFIC JOURNAL OF MATHEMATICS, A NON-PROFIT CORPORATION}

Printed at Kokusai Bunken Insatsusha (International Academic Printing Co., Ltd.), 270, 3-chome Totsuka-cho, Shinjuku-ku, Tokyo 160, Japan.

\section{Copyright (C) 1975 by Pacific Journal of Mathematics} Manufactured and first issued in Japan 


\section{Pacific Journal of Mathematics}

\section{Vol. 57, No. $2 \quad$ February, 1975}

Norman Larrabee Alling, On Cauchy's theorem for real algebraic curves with boundary .......

Daniel D. Anderson, A remark on the lattice of ideals of a Prüfer domain ..................

Dennis Neal Barr and Peter D. Miletta, A necessary and sufficient condition for uniqueness of

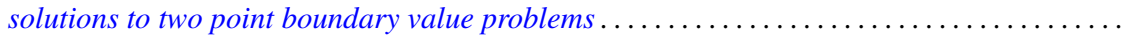

Ladislav Beran, On solvability of generalized orthomodular lattices . . . . . . . . . . ........

L. Carlitz, A three-term relation for some sums related to Dedekind sums . . . . . . . . . .....

Arthur Herbert Copeland, Jr. and Albert Oscar Shar, Images and pre-images of localization

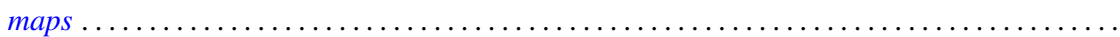

G. G. Dandapat, John L. Hunsucker and Carl Pomerance, Some new results on odd perfect

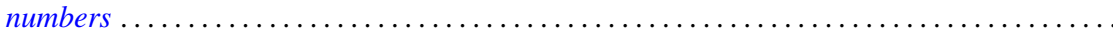

M. Edelstein and L. Keener, Characterizations of infinite-dimensional and nonreflexive

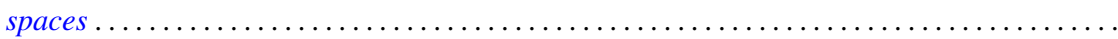

Francis James Flanigan, On Levi factors of derivation algebras and the radical embedding

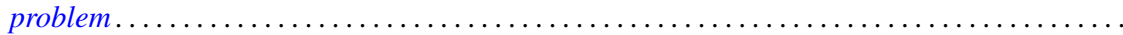

Harvey Friedman, Provable equality in primitive recursive arithmetic with and without

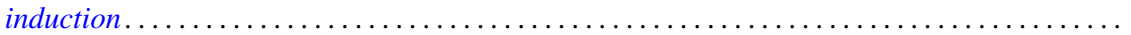

Joseph Braucher Fugate and Lee K. Mohler, The fixed point property for tree-like continua with

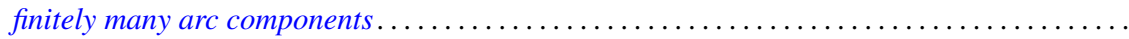

John Norman Ginsburg and Victor Harold Saks, Some applications of ultrafilters in

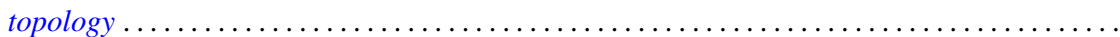

Arjun K. Gupta, Generalisation of a "square" functional equation .....................

Thomas Lee Hayden and Frank Jones Massey, Nonlinear holomorphic semigroups ..........

V. Kannan and Thekkedath Thrivikraman, Lattices of Hausdorff compactifications of a locally

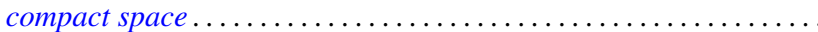

J. E. Kerlin and Wilfred Dennis Pepe, Norm decreasing homomorphisms between group

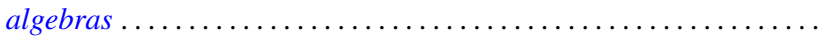

Young K. Kwon, Behavior of $\Phi$-bounded harmonic functions at the Wiener boundary ...

Richard Arthur Levaro, Projective quasi-coherent sheaves of modules .

Chung Lin, Rearranging Fourier transforms on groups...........................

David Lowell Lovelady, An asymptotic analysis of an odd order linear differential equation . . 4475

Jerry Malzan, On groups with a single involution .......................... 481

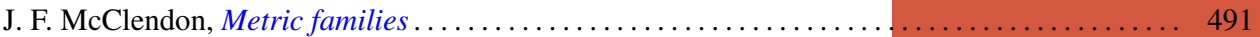

Carl Pomerance, On multiply perfect numbers with a special property .

Mohan S. Putcha and Adil Mohamed Yaqub, Polynomial constraints for finiteness of semisimple rings. .

Calvin R. Putnam, Hyponormal contractions and strong power convergence . . . . . . . . . 531

Douglas Conner Ravenel, Multiplicative operations in $\mathrm{BP} * \mathrm{BP} \ldots \ldots \ldots \ldots \ldots \ldots \ldots \ldots \ldots .539$

Judith Roitman, Attaining the spread at cardinals which are not strong limits . . . . . . . . . 545

Kazuyuki Saitô, Groups of *-automorphisms and invariant maps of von Neumann algebras . . . 553

Brian Kirkwood Schmidt, Homotopy invariance of contravariant functors acting on smooth

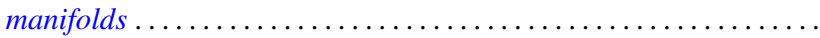

Kenneth Barry Stolarsky, The sum of the distances to $N$ points on a sphere.

Mark Lawrence Teply, Semiprime rings with the singular splitting property.

J. Pelham Thomas, Maximal connected Hausdorff spaces..............

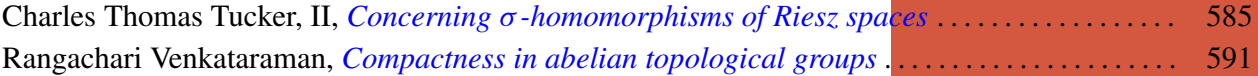

William Charles Waterhouse, Basically bounded functors and flat sheaves . . . . . . . . . . . 597

David Westreich, Bifurcation of operator equations with unbounded linearized part ......... 611

William Robin Zame, Extendibility, boundedness and sequential convergence in spaces of 